this requirement in size, while the abdominal tumor was too large.

'The importance of immediate operation was made plain to the patient, but she refused absolutely to yield consent. In view of the evident urgency of the case and the ignorance of the patient, no heed was paid to her objections, but the operation was insisted upon and was performed on the morning of March 3d. At the time of operation there was moderate flow of blood from the vagina, which had been in progress for several hours. The customary median incision was made and the abdominal tumor at once presented, being without question the pregnant uterus, but astonishingly soft. In order to avoid danger of miscarriage, the uterus was handled as littie as possible, but it being in the way of removing the pelvic tumor it had to be somewhat strongly pressed to one side. In this manipulation no suggestion of fetal parts was folt.

The pelvic tumor proved to be a multilocular cystoma of the right ovary, wade up of a great number of small, thin-walled cysts. The broad ligament was drawn over it by the expanding uterus, so that extraction was difficult. 'The tumor proved so friable that the individual cysts broke down rapidly under the pressure of the fingers in the act of withdrawal from behind the tense broad ligament and hemorrhage was free, but the work was rapidly accomplished and the bleeding immediately checked. 'The tumor was tied off with chromicized catgut, using the cobbler's stitch.

'Tho other ovary was now sought for and was found in the form of a hitherto unsuspected tumor, of the same size and character as the first. It was located behind the fundus of the uterus, high in the abdomen, in contact with the greater curvature of the stomach. It was too large to take in the hand, was slippery and loosely movable, and the pregnant uterus blocked the way for its being brought into view, so that at first some difficulty was experienced in its extraction. Remembering, however, the great friability and vascularity of the former tumor, the fingers were plunged decply into the mass, thus hooking into it and extracting it almost in a single motion.

$\Lambda$ side from the condition of the uterus, nothing so strongly attracted my attention as the broad ligaments. These were in marked contrast to those seen in the operation previously reported, there being absolutely no suggrestion of the greatly enlarged veins so strikingly evident before. In fact, the development of vessels was even less than would be expected in tho presence of two tumors of such size.

The toilet of the peritoneum completed, the wound was closed with continuous layer sutures of chromicized catgut and the patient was returned to the ward in good condition. During the afternoom she was very norvous and restless, and throughout the evening had sharp abdominal pain, with increase of flow from vagiua. $\Lambda$ t 9.40 p. м. she passed a large clot which was mistaken by the house-oflicer for the ovum, and the flow lessening I did not go to the hospital. In the morning a vaginal examination revealed a mass presenting at the vulva, which I removed entire. It proved to be a semi-solid, resembling boiled pearl tapioca, and in quantity about a pint. It was wholly within the vagina, came away easily, und after its removal there was no further hemorrhage. Convales. cence was rapid and uneventful, the patient being discharged well on the twenty-fourth day.
Pathologist's Report, by Marshall H. Bailey, M.D. - "Cystomata of both ovaries. Later, a mass spontaneously evacuated from uterus und vagina received. 'This was a soft mole-like growth, made up of little cysts about the size of swelled tapioca, clear and transparent. The whole mass measured rather less than a pint.

"Diagnosis. - Hydatiform placental mole."

This case presents points of interest both for the gynecologiat and the obstetrician. Both will note at once the difliculty presented in attempting an accurate diagnosis, owing chicefly to the change from the customary signs of pregnancy, due to the presence of $n$ mole, rather than a living embryo in the uterus. 'The rapid enlargement which takes place in such cases, commonly about the third month, had already caused marked thinning of the uterine wall, and the shape of the tumor was strongly ovoid instead of spherical as in ordinary pregnancy.

From the gynecological standpoint, I would particularly call attention to the striking absence of vascular. ity in the pedicle as contrasted with the case before reported. In that report I said: "Ihe ouly unusual condition noted in consequence of the pregrnancy was the extreme vascularity of the pedicle, which consisted of the whole breath of the broad ligament. It seemed a mass of dilated, tortuous veins."

'The explanation of this difference must be found in the fact that the uterus did not contain a living ovum, and nature had therefore failed to provide for a continuance of development.

$\Lambda$ point noted before is again emphasized by the occurrence of pregnancy in such an advanced stage of disease of the ovaries. There seemed no true ovarian tissue left, and yet an ovule was brought to maturity and impregnation resulted, for it is an accepted fact that hydatiform mole cannot occur without conceptioll.

Here, however, our knowledge of the etiology of this condition seems to be at an ond, and in this connection this case assumes its greatest interest. to the obstetrician. In view of the rarity of the disease, this is probably the only case on record in which the inside of the abdomen und pelvis have been observed during its continuance and in the living subject. 'True, the case reveals no conclusive evidence upon which to build a theory, but it at least suggests the possibility that the advanced disease of the ovaries may be responsible: for a lessened vitality in the ovum, hence leading to the disease of the chorion and the death of the fetus. The prompt delivery after the operation cannot be attributed to the latter, as hemorrhage had begun the day before and expulsion of the mass could not long have been delayed.

\section{A CASE OF TE'TANY.}

HY .OSHUA C. IIUBBA KI), M.1)., MOH'TON.

Waltel E. O. W., fourteen monthis old, entered the summer hospital on August 15, 1898, with a moderately severe attack of formental diarrhea.

Physical Examination.-Well developed and poorly nourished; weight eleven pounds four and one-hali ounces; head large and square; two upper incisors only teeth present; chest rather narrow. Rosary present; abdomen prominent; very small umbilical hernia; very large epiphyses at wrists and ankles; 
phimosis with retained smegma; tibia slightly bent outward; heart and lungs negative.

During the last of August his temperature rose and a series of fluctuating swellings came on the back of his head. The first one that was opened contained only serum, but the second a little pus. The suboccipital glands were enlarged to the size of beans and the induration and swelling extended down the neck and round onto the tace.

September 6th. Last night a suclden acute attack with the following symptoms: 'Thumbs flexed across palms, fingers flexed,-wrists flexed, knoes slightly bent. feet in position of talipes equinus. All these joints held rigid by the tonic spasm of the muscles. At times neck rigid; at times chin can be brought down onto chest. Back rigid. Abdomen very much distended. Knee-jerks absent. No involvement, of face. Pupils equal and react to light.

The spastic condition gradually disappeared so that by September 12th the only evidence of it was the increase in the knee-jerks.

'The attack had no effect on the diarrhen, which continued to improve slowly, or the appetite. He lost a little weight during it, but with the cessation of the acute symptoms began to gain again and left the hospital on September 13th, weighing eleven pounds fourteen ounces.

\section{SQRedical Brogregg.}

\section{REPOR'T ON OR'THOPEDIC SURGERY.}

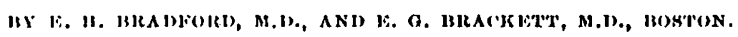

\section{POLYARTILITIS DEFORMANS IN CHILDREN.}

'I'scukin Now ${ }^{1}$ describes this affection and considers it as occurring especially in patients with an hereditary Пунстаsia, influenced by general or local conditions, which, irritating the joints, bring out acule or subacute rheumatic symptoms. Influenced by these causes, characteristic symptoms develop, namely, hypertrophy of the epiphyses and atrophy of the diaphyses; destruction or fibrous degeneration of the cartilages; $n$ ]teration of the synovial membrane; carly muscular contraction. The chiof changes take place in the bones, especially of the smaller joints. In 49 cases tho aflection began with an acute or subacute onset. Heart complications were seen in only nine cases out of the 49 . $\Lambda$ marked distinction is to be observed between this and the ordinary rheumatism in children, which is not accompanied or followed by deformity or the development of bone exostosis. In an analysis of 400 cases the affection was found to range according to age from one year four months to twenty-five years. The constant current is employed, but, according to the writer, without marked benefit.

Delcourt ${ }^{2}$ contributes an excellent article on the subject, giving an antopsy with carefully recorded observations of the anatomical conditions. A marked distinction is to be made between the enlargement of the joints in the condition and the changes due to the bacillus of tuberculosis. In the condition described a non-tubercular osteomyelitis is to be found at the end of the bone, with fibrous rhoumatoid changes in the periarticular tissues. An x-ray photograph may

1 Centrallsl. f. Chir., p. 853, Auguat 20, 1898.

¿ Rovuo Mensuolle des Mulmdies de l' infunce, ouly, 1898, 329. be of value to determine the non-tubercular nature of the affection.

\section{CONGENTAL High position of the sCAPUi.}

Pitset $^{8}$ describes this unusual deformity, which has erroneously been attributed to an exostosis, and attributes it to an abnormal position of the arm in utero, followed by a consequent alteration in the muscles whereby the deformed position is maintained. It is not to be confounded with the non-congenital high position of the scapula seen in the curvature of the cervical region in lateral curvature.

'lhe treatment of this congenital form, which has been successfully performed by Bolton and Hoffa, consists in operative interference. An incision is made along the forward border of the cucullaris muscle; the muscle is separated from its scapular attachment; the curve of the scapula corresponding to the attachment of the muscle is cut off by meaus of a bone forceps and the wound is packed.

\section{CERVICAL, RIB WITH OPERATION.}

Iloward J. Williams" reports a case of this rather unusual affection, in which the uso of the skingraphs for methods of location of diagnosis was misleading. 'The case presented early the symptoms of a prominence above the clavicle, which later increased in size, and became troublesome. It was apparently not connected with the clavicle, but moved with forced respiratory effort. It was at first thought to be either a proninent transverse process, or exostosis, or enchondroma coming from the first rib. Later the tumor became troublesome, and was removed by an incision between the sterno-mastoid and the trapezius. There was found a superumerary rib about three inches long, extending from the transverse process of probably the sixth cervical vertebra. It presented a joint in the middle portion, which allowed by ligamentous union a limited motion. It gave attachment to some, of the muscle fibres, probably one of the spleni, and also of muscle fibres which passed to the first rib.

The author considers that the failure of the skiagraph, either for purposes of locating this tumor, or determining its character, is of importance. The diagnosis would not have been made if reliance had been placed entirely upon this.

\section{Myosilis ossmicans.}

De la Camp" reports a case of this affection, whero by means of radiographic demonstrations the affection is shown to he more an excessive development of exostoses than an ossifying inflammation of muscle.

Boks "considers this affection in children the result of an inlerited tendency, although the initial canse is a tramma. In a child two and one-half years of age, described by him, hard painful regions developed under febrile symptoms in different muscles, which in part diminished, but in places developed fremanent thicken. ing of the consistency of bonte. In some regions the muscles became almost entirely of hard masses as in others they were sof and atrophic. 'The muscles of the neck were first attacked and later the muscles of the thorax, especially of the right shoulder. In the abdominal muscles isolated hard kernels could be folt. The affection, in the opinion of the writer, is not an exostosis,

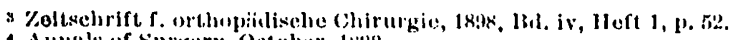
- Aumals of Surgery, Oetober, 1:

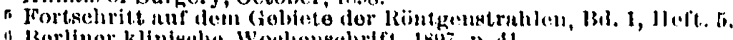
"Borlinor klinisches Wouhensehrifi, 1k:1, p. 41. 